\title{
Occupational exposure to solvent mixtures: effects on health and metabolism
}

Hirohiko Ukai, Shiro Takada, Shunen Inui, Yoshiko Imai, Toshio Kawai, Shin-ichiro Shimbo, Masayuki Ikeda

\begin{abstract}
Exposure monitoring by personal difusive samplers, biological monitoring of toluene exposure by urinary hippuric acid determination, haematology, serum biochemistry for liver function, and a subjective symptom survey by questionnaire were conducted on 303 male solvent workers. They were exposed to a mixture of solvents including toluene (geometric mean $18 \mathrm{ppm}$ ), methyl ethyl ketone (MEK; 16 ppm), isopropyl alcohol (IPA; $7 \mathrm{ppm})$, and ethyl acetate (9 ppm). The intensity was mostly below unity using the additiveness formula based on current Japanese occupational exposure limits, but more than eight times unity at the maximum. The results were compared with the findings in 135 non-exposed male workers of similar ages. Haematology and liver function tests did not show any exposure related abnormality, and subjective symptoms were mostly related to central nervous system depression and local irritation. Further analysis suggested that the irritation effects were not related to exposure to MEK. Analysis of the relation between toluene exposure and hippuric acid excretion in urine showed that there was no metabolic interaction between MEK and toluene, or between IPA and toluene. Overall, therefore, it is concluded that there was no sign or symptom detected to suggest anything other than toluene toxicity, that there was no evidence to indicate any modification of toluene toxicity or metabolism due to coexposure, and that the additiveness assumption is reasonable for risk assessment for the combination of solvents under these exposure conditions.
\end{abstract}

(Occup Environ Med 1994;51:523-529)

Organic solvents are common materials in modern industries. They are generally used as mixtures, typically in thinner, adhesive, ink, and paint preparation. ${ }^{1-3}$ This contrasts with the fact that the toxicity profiles are usually described in textbooks as those of single, pure chemicals, and that toxicity of solvent mixtures is uncertain.

It is to be expected that the toxicity of solvent mixtures will vary depending on the toxicity of the individual solvent constituents. It is, however, also true that toluene is the solvent present in the largest proportion in many cases, ${ }^{1-3}$ suggesting that the major toxicity profile may be predominantly determined by toluene, with other solvents as minor toxicity modifiers.

The present study was initiated to investigate this possibility by examining dominant toxicity pictures among solvent workers exposed primarily to toluene, together with other common solvents such as ethyl acetate, methyl ethyl ketone (MEK), and isopropyl alcohol (IPA).

\section{Materials and methods}

WORKERS STUDIED

The study was conducted in the second half of working weeks (on Thursdays and Fridays). In total, 303 male solvent exposed workers and 136 male non-exposed controls were studied. The solvent exposed employees worked in printing, ink production, or surface treatment plants (where the surface of materials were treated with plastics disolved in solvents). Control subjects were office workers and were recruited from clerical sections of the same factories. Efforts were made to collect controls with ages comparable with those of the exposed subjects; the control subjects were, however, on average older than the exposed subjects, although there was a considerable overlap in the age distributions (table 1).

\section{COLLECTION OF SAMPLES}

For the determination of the time weighted average (TWA) exposure concentration, each

\section{Table 1 Demographic and exposure profile}

\begin{tabular}{lcc}
\hline Item & Exposed group & $\begin{array}{l}\text { Control } \\
\text { group }\end{array}$ \\
\hline No & 303 & 135 \\
Age (y (SD)) & $32.9(11 \cdot 4)$ & $44 \cdot 4$ \\
& & $(11 \cdot 2)$
\end{tabular}

Exposure:

$\begin{array}{llll}\text { Toluene } & 17.6 \quad(3.40): 479 \star & 17.6 \quad(3.40) / 303 \dagger\end{array}$

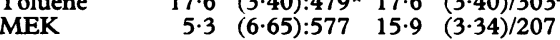

IPA

Ethyl acetate

Xylenes

$\begin{array}{llll}4.3 & (5.57): 741 & 8.6 & (4.00) / 229\end{array}$

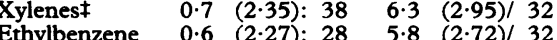

$\begin{array}{llll}\text { Sum§ } & 0.31(2.05): & 8.4 & 0.33(2.94) / 303\end{array}$ ${ }^{\star}$ GM (GSD): the maximum (ppm), calculated with 303 determinations replacing $0 \mathrm{ppm}$ with $0.5 \mathrm{ppm}$.

I ppm cases.
†Sum of three xylene isomers.

SSummation of solvent concentrations from the additiveness formula, ${ }^{5}$ and based on the occupational exposure limits of $100 \mathrm{ppm}$ for toluene, xylenes, and ethylbenzene, $200 \mathrm{ppm}$ for MEK, and 400 ppm for IPA and ethyl acetate. ${ }^{24}$
606-01, Japan.

Accepted for publication 18 March 1994 
solvent exposed worker was equipped with a diffusive sampler ${ }^{4}$ worn at chest level from the beginning of the shift (at around 0900) until the time of urine collection (at around 1600).

The shift ended at 1700. Near the end (at around 1600 ), they were invited to a solvent free examination room for sampling of venous blood and urine, and were requested to fill in subjective symptom questionnaires.

\section{ANALYSIS OF SOLVENTS IN THE ENVIRONMENTAL AIR}

After exposure, each carbon cloth in the sampler was extracted with carbon disulphide. The extract was analysed with an FID-gas chromatography apparatus as previously described. ${ }^{4}$ Because the solvent workers were exposed to more than one solvent in most cases, the sum (the summation index) was calculated from the additiveness formula ${ }^{5}$ for overall exposure evaluation.

\section{URINALYSIS}

Each worker was asked to pass urine between 1300 and 1400 and then urine discharged at between 1500 and 1600 was sampled. The samples were analysed for hippuric acid by high pressure liquid chromatography with an automated liquid sampler ${ }^{6}$ from which $2 \mu \mathrm{l}$ urine was introduced per injection after filtration through a membrane. The concentrations of the urinary metabolites were expressed as measured, or after correction for creatinine concentration ${ }^{7}$ or a specific gravity of urine of $1.016 .^{8}$ Creatinine and specific gravity were measured by colorimetry and refractometry respectively.

\section{CLINICAL EXAMINATIONS AND SUBJECTIVE SYMPTOM SURVEYS}

The items studied in haematology were erythrocyte counts, leucocyte counts, thrombocyte counts, haemoglobin concentration, and packed cell volume, and those in serum biochemistry were aspartate aminotransferase (ASAT; EC2 $6 \cdot 1 \cdot 1$ ), alanine aminotransferase (ALAT; EC2.6.1.2), $\gamma$-glutamyl transpeptidase $(\gamma$-GTP; EC2.3.2.1), alkaline phosphatase $(E C 3 \cdot 1 \cdot 3 \cdot 1)$, lactate dehydrogenase (LDH; EC1 $1 \cdot 1 \cdot 27$ ), leucine aminopeptidase (LAP; EC3.4.1.1), total cholesterol, high density lipoprotein cholesterol, triglyceride, blood urea nitrogen, uric acid, and creatinine. They were measured by conventional methods. For comparison between the exposed and control groups, the results were classified into three categories-normal, borderline, and abnormal cases-taking the normal/log normal distribution of the values and clinical experiences into consideration as previously described. ${ }^{9}$ Activities of ASAT and ALAT were evaluated in combination in accordance with clinical practice. ${ }^{9}$

Subjective symptoms were surveyed by self administered questionnaires with 12 questions about symptoms during work and 57 questions about symptoms when not at work and in the past three months ${ }^{1011}$; the answers were confirmed in a medical interview. The prevalence of the subjective symptoms was calculated ${ }^{9}$ as:

$$
\begin{gathered}
\text { number of affirmative answers by the group } \\
\begin{array}{c}
\text { (number of the subjects in the group) } \times \\
\text { (number of questions) }
\end{array}
\end{gathered}
$$

SELECTION OF THE EXPOSED SUBJECTS TO FORM SUBGROUPS BY COEXPOSURE TO ANOTHER SOLVENT

Among the 303 exposed workers, 207 subjects were exposed to MEK as well as toluene and other solvents, and 108 subjects were exposed to IPA as well as to toluene and others. To detect possible effects of MEK or IPA coexposure on toluene, MEK or IPA exposed subjects were matched by toluene exposure intensity with MEK or IPA nonexposed subjects. In practice, toluene exposure intensity was uneven between the MEK exposed and MEK non-exposed groups or between the IPA exposed and IPA nonexposed groups, and only 74 pairs (the + MEK group and the - MEK group) were available among MEK exposed and MEK non-exposed people, because only seven MEK exposed subjects were exposed to $<4$ ppm toluene by contrast with 29 MEK nonexposed subjects. For IPA exposure, only 95 pairs (the + IPA group and the - IPA group) were established primarily due to lack of high toluene exposure among the IPA exposed subjects.

\section{STATISTICAL ANALYSIS}

A $\log$ normal distribution was assumed for evaluation of the solvent vapour concentration. ${ }^{11-14}$ In calculating the geometric mean (GM) and geometric SD (GSD), 0 ppm was replaced with $0.5 \mathrm{ppm}$ for practical reasons. When the exposure-excretion correlation was calculated, the control group was employed to define the non-exposed level (the metabolite level without the exposure). In practice, the correlation was calculated utilising the combination of the control group with the exposed group. For statistical analysis, $\chi^{2}$ test, Student's $t$ test, regression analysis, and multivariate analysis were used.

\section{Results}

EXPOSURE TO ORGANIC SOLVENTS

Analysis of organic solvent vapours in ambient air collected by personal diffusive sampling (table 1) confirmed that the main solvent to which the workers were exposed was toluene. Ethyl acetate, MEK, and IPA were detected also in many but not all samples, depending on the workers studied. By contrast, xylenes and ethylbenzene were only found in a few samples.

The toluene concentration as a whole was rather low (GM 17.6 ppm), although some workers were exposed to up to $479 \mathrm{ppm}$. Of particular interest is the presence of MEK. Whereas this solvent was only detected in about two thirds of the total samples, the concentration was comparable to (GM 15.9 ppm) or even higher (577 ppm as the 
maximum) than toluene concentration if it was present. When the sum of all the solvent concentrations was calculated from the additiveness formula (the summation index), ${ }^{5}$ the GM was about one third, whereas the maximum was in excess of eight times unity.

Statistical analysis (table 2) indicated that solvent concentrations were not independent of each other, and that there were significant

Table 2 Correlation among the solvent concentrations

\begin{tabular}{llllll}
\hline & $\begin{array}{l}\text { Ethyl- } \\
\text { benzene }\end{array}$ & Xylenes & $\begin{array}{l}\text { Ethyl } \\
\text { acetate }\end{array}$ & IPA & MEK \\
\hline Toluene & -0.076 & -0.067 & $0.573^{\star \star}$ & $0.871^{\star \star}$ & $0.598^{\star \star}$ \\
MEK & -0.112 & -0.107 & 0.057 & $0.647^{\star \star}$ & \\
IPA & -0.072 & -0.071 & $0.443^{\star \star}$ & & \\
Ethyl & & & & \\
$\quad$ acetate & -0.067 & -0.068 & & & \\
Xylenes & $0.971^{\star \star}$ & & & & \\
\hline
\end{tabular}

${ }^{\star \star} \mathrm{p}<0.01$. Values are correlation coefficients.

Table 3 Distribution of normal, borderline, and abnormal cases in haematology and serum biochemistry

\begin{tabular}{lcll}
\hline Item (unit) & Normal range & Control group & Exposed group \\
\hline No of workers & & 135 & 303 \\
Haematology: & & & \\
$\quad$ Haemoglobin $(\mathrm{g} / 100 \mathrm{ml})$ & $13 \cdot 0-17 \cdot 0$ & $129 / 5 / 1$ & $293 / 9 / 1$ \\
$\quad$ Leucocytes $\left(\times 10^{3} / \mathrm{mm}^{3}\right)$ & $4 \cdot 0-8 \cdot 0$ & $123 / 12 / 0$ & $287 / 16 / 0$ \\
Serum biochemistry: & & & \\
$\quad \gamma$-GTP (IU/1) & $6-45$ & $107 / 13 / 15$ & $262 / 23 / 18$ \\
ASAT and ALAT $(\mathrm{IU} / 1)^{\star}$ & $8-40,5-35 \dagger$ & $26 / 6 / 3$ & $281 / 18 / 4$ \\
\hline
\end{tabular}

Values for groups are numbers of normal/borderline/abnormal cases. There was no significant difference in the distribution between control and exposed groups.

${ }^{\star}$ ASAT and ALAT activities were evaluated in combination.

†Normal ranges for both ASAT and ALAT are shown. $(p<0.01)$ correlations between toluene and MEK, toluene and IPA, toluene and ethyl acetate, IPA and MEK, IPA and ethyl acetate, and xylenes and ethylbenzene. Scattering of the concentrations around the regression lines were, however, wide, and the statistical significance of the correlations seemed to be due to large numbers of determinations. Figure 1 gives the scatter diagram of toluene $v$ MEK and toluene $v$ IPA. No significant $(p>0.05)$ correlation was detected between toluene and xylenes, toluene and ethylbenzene, or MEK and ethyl acetate. The lack of correlation in the first two cases was contrary to our expectation that xylenes and ethylbenzene might be present as toluene impurities.

CLINICAL SIGNS

Table 3 summarises results on haemoglobin concentrations, leucocyte counts, $\gamma$-GTP, ASAT and ALAT as examples of haematology and liver function. For haematology, a few examinees in the control group and the exposed group fell in the borderline category due to subclinical anaemia or subclinical leucocytosis, but the distribution pattern did not differ significantly $(p>0.05)$ between the two groups. $\gamma$-GTP concentrations were raised in about $15 \%$ of the examinees in both groups. There was no significant difference $(p>0.05)$ between the two groups. Activities of ASAT and ALAT were also increased in some $7 \%$ of the subjects studied, but with no significant $(\mathrm{p}>0.05)$ difference in the distribution between the two groups.
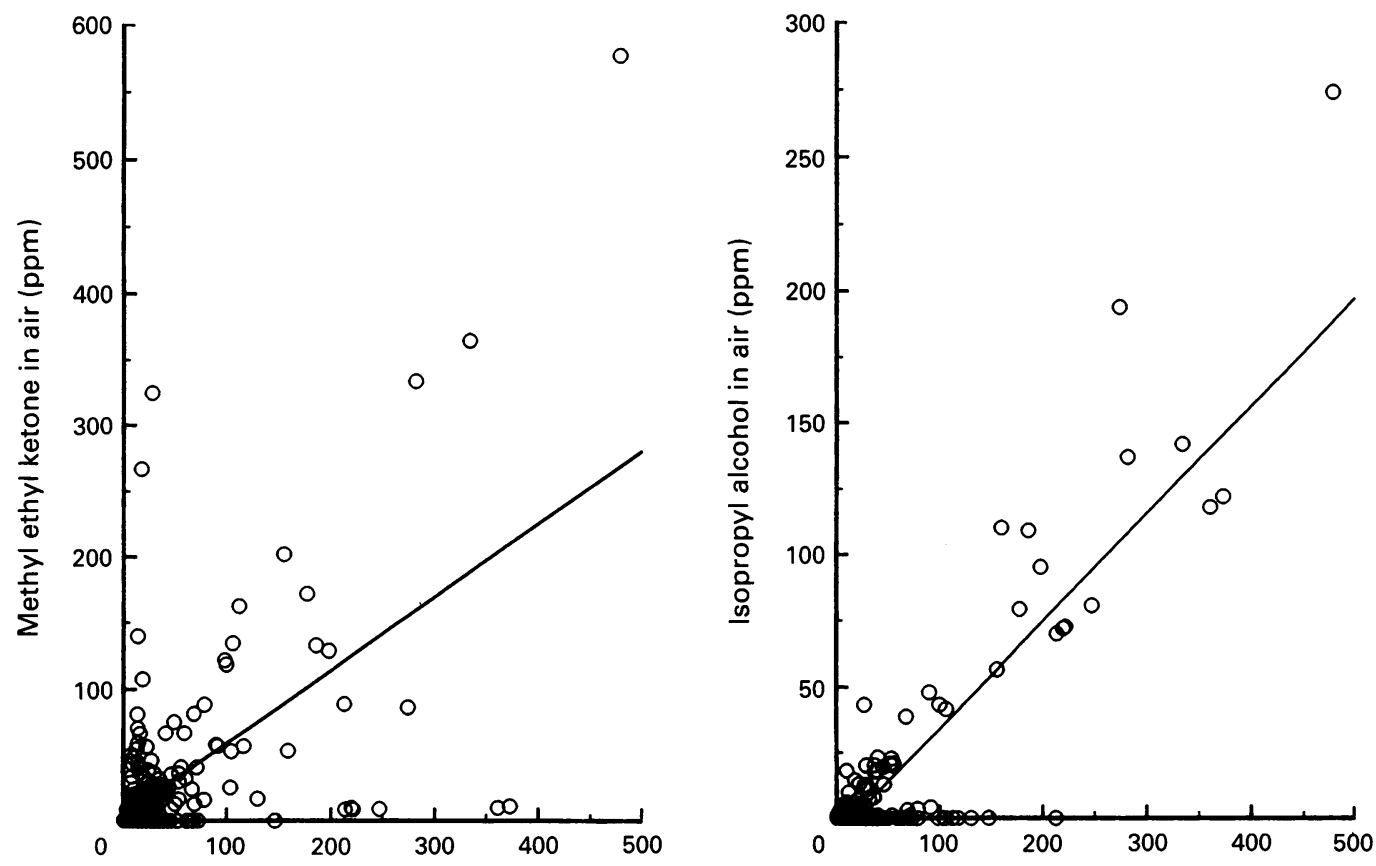

Toluene in air (ppm)

Figure 1 Scatter diagrams of the relation between toluene and methyl ethyl ketone (MEK), and toluene and isopropyl alcohol (IPA) in workroom air. (A) Toluene $v$ MEK (B) Toluene $v$ IPA. The lines are calculated regression lines of $y=3.34+0.554 x(r=0.598, p<0.01, n=303)$ and $z=-6.73+0.408 x(r=0.871, p<0.01, n=303)$, where $x, y$, and $z$ are concentrations (ppm) of toluene, methyl ethyl ketone, and isopropyl alcohol, respectively. 
Table 4 Prevalence of subjective symptoms

\begin{tabular}{|c|c|c|c|c|c|c|c|c|}
\hline \multirow{2}{*}{$\begin{array}{l}\text { Subjective } \\
\text { symptom }\end{array}$} & \multirow{2}{*}{$\begin{array}{l}\text { No of } \\
\text { questions }\end{array}$} & \multirow[b]{2}{*}{ Parameter } & \multirow[b]{2}{*}{ Controls } & \multicolumn{5}{|c|}{ Exposed group $\neq$} \\
\hline & & & & Total & $\leqslant 0.2$ & $>0.2-0.5$ & $>0.5-1.0$ & $>1.0$ \\
\hline No of subjects & & \multirow{4}{*}{$\begin{array}{l}\text { AAS } \\
\text { Prevalence (\%)ף } \\
\text { AA } \\
\text { Prevalence (\%) }\end{array}$} & \multirow{4}{*}{$\begin{array}{c}135 \\
69 \\
4 \cdot 3 \\
468 \\
5 \cdot 9\end{array}$} & \multirow{4}{*}{$\begin{array}{c}303 \\
497 \\
13 \cdot 7^{\star \star} \\
1320 \\
7 \cdot 4^{\star \star}\end{array}$} & \multirow{4}{*}{$\begin{array}{c}78 \\
85 \\
9 \cdot 1 \\
341 \\
7 \cdot 4\end{array}$} & \multirow{4}{*}{$\begin{array}{l}135 \\
201 \\
12 \cdot 4 \\
473 \\
6.0\end{array}$} & \multirow{4}{*}{$\begin{array}{c}56 \\
101 \\
15 \cdot 0 \\
270 \\
8 \cdot 2\end{array}$} & \multirow{4}{*}{$\begin{array}{l}34 \\
110 \\
27 \cdot 0+t \\
236 \\
11 \cdot 8+t\end{array}$} \\
\hline During work & 12 & & & & & & & \\
\hline & & & & & & & & \\
\hline Not at work & 57 & & & & & & & \\
\hline
\end{tabular}

$\star \star \mathrm{p}<0.01 v$ controls

tp $<0.01$ for difference among the four exposed subgroups.

fClassification by summation of solvent concentrations as defined in the footnote to table 1 .

Numbers of affirmative answers.

TFor definition of prevalence of symptoms, see materials and methods.

\section{INCREASE IN PREVALENCE OF SUBJECTIVE} SYMPTOMS

Subjective symptoms were evaluated separately for those occurring during work and for those not at work. As well as the comparison between the exposed group and the nonexposed control group, the exposed subjects were divided into subgroups by use of the summation index as a total exposure indicator (table 4) for comparison among the subgroups of different exposure intensity. Whereas the subjective symptoms both during work and not at work were significantly

Table 5 Symptoms during work with significant difference in prevalence

\begin{tabular}{|c|c|c|c|c|}
\hline \multirow[b]{2}{*}{ Subjective symptoms $\ddagger$} & \multicolumn{2}{|c|}{ Prevalences } & \multicolumn{2}{|c|}{ Influential solvents } \\
\hline & Controls & Exposed & The most & The 2nd most \\
\hline $\begin{aligned} \text { During work: } \\
1 \text { Irritation in eyes } \\
3 \text { Nasal irritation } \\
4 \text { Unusual smell } \\
5 \text { Sore throat } \\
6 \text { Unusual taste } \\
9 \text { Floating sensation } \\
10 \text { Drunken feeling }\end{aligned}$ & $\begin{array}{l}8.1 \\
1.5 \\
1.5 \\
4.4 \\
0.7 \\
2.2 \\
1.5\end{array}$ & $\begin{array}{l}19 \cdot 8^{\star \star}+7 \\
37 \cdot 3^{\star \star}+7 \\
26 \cdot 1^{\star \star}+7 \\
15 \cdot 5^{\star \star} \\
5 \cdot 3^{\star \star}+4 \\
14 \cdot 5^{\star \star}+7 \\
14 \cdot 5^{\star \star}+7\end{array}$ & $\begin{array}{l}\text { Toluene } \\
\text { Ethyl acetate } \\
\text { Toluene } \\
\text { (None) } \\
\text { Toluene } \\
\text { Toluene } \\
\text { Toluene }\end{array}$ & MEK \\
\hline $\begin{array}{l}\text { When not at work: } \\
103 \text { Dizziness } \\
110 \text { Lightheadedness } \\
111 \text { Muddleheadedness } \\
118 \text { Fainting after sudden } \\
\text { standing up } \\
122 \text { General dullness } \\
123 \text { Dullness in extremities } \\
130 \text { Body weight loss } \\
141 \text { Reduced sense of smell } \\
151 \text { Rough skin }\end{array}$ & $\begin{array}{l}1.5 \\
0.0 \\
3 \cdot 0 \\
\\
5 \cdot 2 \\
8 \cdot 1 \\
0 \cdot 7 \\
4 \cdot 4 \\
2 \cdot 2 \\
8 \cdot 1\end{array}$ & $\begin{array}{c}5 \cdot 6^{\star \star}+t \\
7 \cdot 3^{\star \star} \\
11 \cdot 9^{\star \star} \\
15 \cdot 2^{\star \star} \\
25 \cdot 7^{\star \star} \\
8 \cdot 3^{\star \star} \\
12 \cdot 2^{\star \star} \\
11 \cdot 2^{\star \star} \\
21 \cdot 8^{\star \star}+\dagger\end{array}$ & Toluene & IPA \\
\hline
\end{tabular}

$\star \star \mathrm{p}<0.01 v$ controls; $\mathrm{tt} \mathrm{p}<0.01$ for difference among subgroups when the exposed group was classified into those exposed at $\leqslant 0.2,>0.2-0.5,>0.5-1.0$, and $>1.0$ (unity calculated by the classified into those expos Symptoms listed are those with significant differences $(p<0.01)$ in the prevalence between the

control and exposed groups.

†Symptoms are coded after Uchida et al."

Values are prevalence in \% for the symptom prevalence as defined in materials and methods.

ISolvents were identified by mutivariate analysis, taking six solvent concentrations as independent variables. Calculations were made only in cases shown by two daggers.

Table 6 Solvent exposure of subgroups as classified by exposure to MEK and IPA

\begin{tabular}{|c|c|c|c|c|}
\hline \multirow{3}{*}{$\begin{array}{l}\text { Exposure } \\
\text { to solvents }\end{array}$} & \multicolumn{4}{|l|}{ Classification by } \\
\hline & \multicolumn{2}{|l|}{$M E K$} & \multicolumn{2}{|l|}{$I P A$} \\
\hline & $+M E K$ & $-M E K$ & $+I P A$ & $-I P A$ \\
\hline $\begin{array}{l}\text { No } \\
\text { Toluene } \\
\text { MEK } \\
\text { IPA } \\
\text { Ethyl acetate } \\
\text { Xylenes } \\
\text { Ethylbenzene }\end{array}$ & $\begin{array}{l}74 \\
15.8(2.68) \\
12.1(3.48) \\
1.3(3.35)^{\star \star} \\
4.5(3.75)^{\star \star} \\
0.6(1.61)^{\star \star} \\
0.6(1.66)^{\star}\end{array}$ & $\begin{array}{l}74 \\
15 \cdot 2(2 \cdot 76) \\
0.7(2 \cdot 51) \\
1.5(4 \cdot 96) \\
1.3(4 \cdot 17) \\
0.8(2 \cdot 84)\end{array}$ & $\begin{array}{l}95 \\
20.3(2.51) \\
10.0(5.09)^{\star \star} \\
4.6(3.18) \\
8.3(4.48)^{\star \star} \\
0.5(1.53)^{\star \star} \\
0.6(1.66)^{\star \star}\end{array}$ & $\begin{array}{l}95 \\
20.3(2.52) \\
4.6(5.92) \\
-2.9(4.41) \\
0.8(3.11) \\
0.8(2.84)\end{array}$ \\
\hline
\end{tabular}

${ }^{\star} \mathrm{p}<0.05 ;{ }^{\star \star} \mathrm{p}<0.01 v$ the paired value.

Values are GM (GSD) ppm. $(p<0.01)$ more prevalent in the exposed group than in the controls, the increase was larger for the symptoms during work (more than threefold) than for the symptoms not at work (well below twofold). The subgrouping of the exposed groups showed a significant $(p<0.01)$ dose associated increase in symptoms both during work and not at work. The prevalence of symptoms during work increased considerably when the summation index was in excess of 1 , whereas the change in the prevalence was less remarkable when the symptoms not at work was studied.

Evaluation of each symptom during work (table 5) disclosed that the prevalence of seven symptoms out of the 12 was significantly $(p<0.01)$ greater in the exposed group than in the controls, and that dose dependency was confirmed in six symptoms among the seven. Graphical presentation of the dose response relation (fig 2) shows that the prevalence of two symptoms, irritation in eyes and nasal irritation, and possibly that of a drunken feeling increased when the exposure was above a certain level $(0.5$ to 1.0$)$ whereas the prevalence of floating sensation was linearly increased as a function of exposure intensity.

By contrast, only two symptoms (dizziness and rough skin) showed significant $(p<0.01)$ dose dependency among the 57 symptoms when not at work. The difference in the prevalence between the exposed group and the control group was, however, significant $(p<0.01)$ for nine symptoms (table 5).

Table 7 Symptoms by subgroups as classified by exposure to $M E K$ and IPA

\begin{tabular}{|c|c|c|c|c|}
\hline \multirow[b]{3}{*}{ Subjective symptom ${ }^{\star}$} & \multicolumn{4}{|c|}{ Classification by } \\
\hline & \multicolumn{2}{|c|}{$M E K$} & \multicolumn{2}{|l|}{$I P A$} \\
\hline & $+M E$ & $-M E K$ & $+I P A$ & $-I P A$ \\
\hline $\begin{aligned} \text { During work: } \\
1 \text { Irritation in eyes } \\
3 \text { Nasal irritation } \\
4 \text { Unusual smell } \\
5 \text { Sore throat } \\
6 \text { Unusual taste } \\
9 \text { Floating sensation } \\
10 \text { Drunken feeling }\end{aligned}$ & $\begin{array}{l}23 \cdot 0 \\
39 \cdot 1 \\
28 \cdot 3 \\
16 \cdot 2 \\
12 \cdot 2 \\
17 \cdot 5 \\
12 \cdot 2\end{array}$ & $\begin{array}{r}16 \cdot 2 \\
23.0 \\
20.3 \\
9.5 \\
2.7 \\
9.5 \\
8.1\end{array}$ & $\begin{array}{r}16.8 \\
45.3 \\
33.7 \\
15.8 \\
5.3 \\
14.7 \\
12.6\end{array}$ & $\begin{array}{r}22.1 \\
35.8 \\
26.3 \\
17.9 \\
7.4 \\
14.7 \\
14.7\end{array}$ \\
\hline $\begin{array}{l}\text { Not at work: } \\
103 \text { Dizziness } \\
151 \text { Rough skin }\end{array}$ & $\begin{array}{r}2 \cdot 7 \\
17 \cdot 6\end{array}$ & $\begin{array}{r}5.4 \\
14.9\end{array}$ & $\begin{array}{r}2 \cdot 1 \\
15 \cdot 8\end{array}$ & $\begin{array}{r}9 \cdot 5 \\
14 \cdot 7\end{array}$ \\
\hline
\end{tabular}

*Symptoms are coded after Uchida et al." 

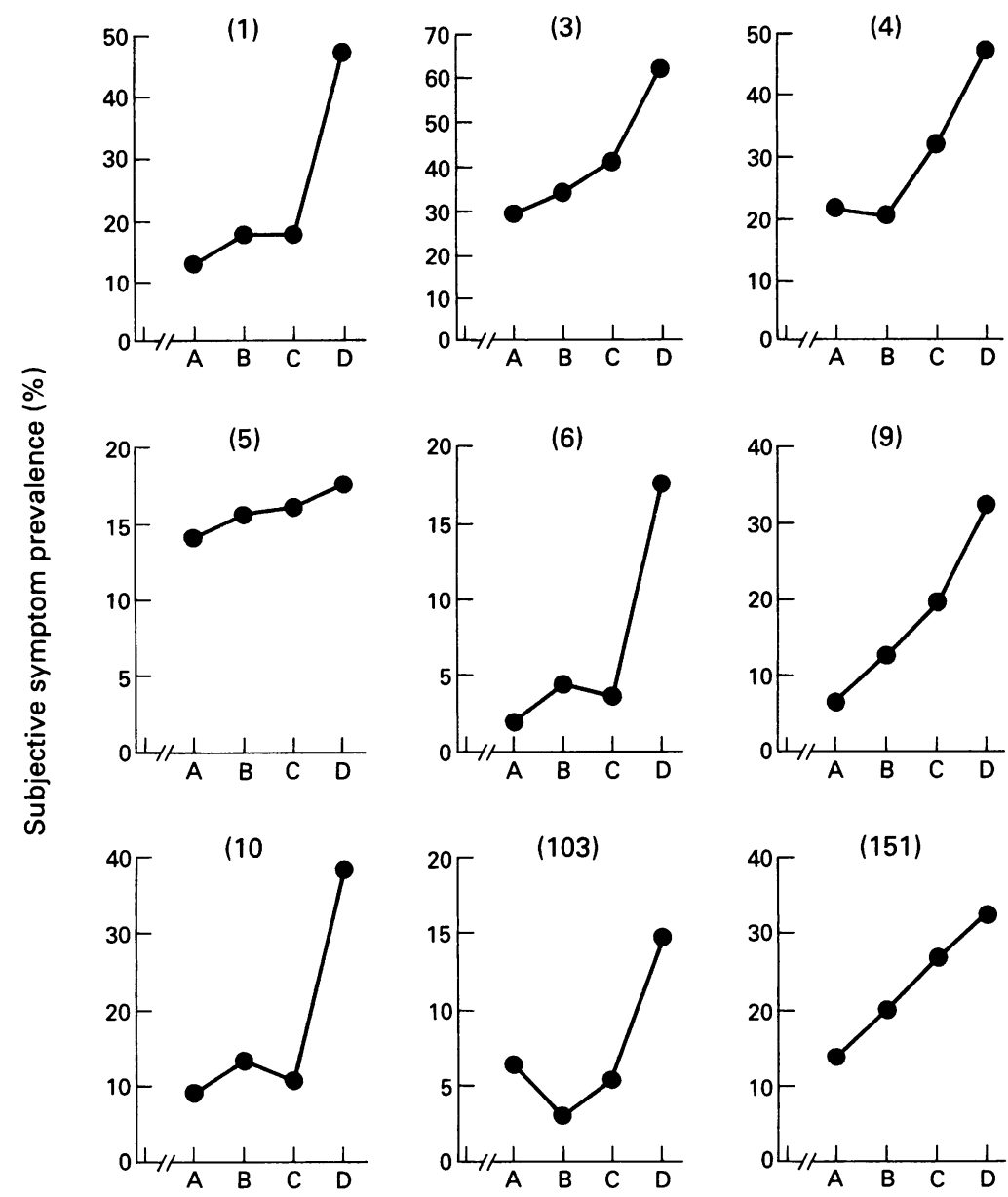

Solvent in air

Figure 2 Symptoms during work and when not at work, by intensity of exposure.

Symptoms with code numbers of 1 to 10 are symptoms during work, and the code numbers 103 and 151 are symptoms when not at work. Exposure intensity is expressed in terms of unity from the additiveness formula - that is, $A \leqslant 0 \cdot 2, B>0 \cdot 2-0 \cdot 5, C>0 \cdot 5-1 \cdot 0$, and $D>1 \cdot 0$. The numbers of workers in the subgroups $A, B, C$, and $D$ are $78,135,56$, and 34 respectively. For definition of prevalence, see materials and methods.

Trials were made to identify the most influential solvent in inducing each symptom. For this purpose, multivariate analysis was performed taking each solvent concentration as independent variable (although they were in fact not independent in many cases as shown in table 2). Toluene was the most

Table 8 Correlation of urinary hippuric acid excretion with environmental toluene exposure: comparison between single and mixture exposure

\begin{tabular}{|c|c|c|c|}
\hline \multirow[b]{2}{*}{ Case } & \multicolumn{3}{|c|}{ Regression parameter } \\
\hline & $a$ & $\beta$ & $r$ \\
\hline $\begin{array}{l}\text { The present study with mixed exposure: } \dagger \\
\text { No correction (observed value) (mg/l) } \\
\text { Corrected for: }\end{array}$ & $747(653-1417)$ & $14.9(13 \cdot 3-16.5)$ & 0.655 \\
\hline $\begin{array}{l}\text { Creatinine }(\mathrm{mg} / \mathrm{g} \text { creatinine }) \\
\text { Specific gravity }(1 \cdot 016)(\mathrm{mg} / \mathrm{l})\end{array}$ & $\begin{array}{l}536(486-583) \\
495(448-542)\end{array}$ & $\begin{array}{c}13.9(13 \cdot 1-14 \cdot 7) \\
8 \cdot 0(7 \cdot 2-8 \cdot 8)\end{array}$ & $\begin{array}{l}0.840 \\
0.686\end{array}$ \\
\hline $\begin{array}{l}\text { Exposure to toluene only: } \ddagger \\
\text { No correction (observed value) (mg/l) }\end{array}$ & $271(-2-544)$ & $31 \cdot 1(24 \cdot 9-37 \cdot 3)$ & 0.803 \\
\hline $\begin{array}{l}\text { Corrected for: } \\
\text { Creatinine (mg/g creatinine) } \\
\text { Specific gravity }(1.016)(\mathrm{mg} / \mathrm{l})\end{array}$ & $\begin{array}{l}361(116-607) \\
273(114-433)\end{array}$ & $\begin{array}{l}15 \cdot 8(10 \cdot 2-21 \cdot 4) \\
16 \cdot 2(12 \cdot 6-19 \cdot 8)\end{array}$ & $\begin{array}{l}0.606 \\
0.768\end{array}$ \\
\hline
\end{tabular}

$\star a$ and $\beta$ are parameters of a calculated regression line so that $y=a+\beta x$, where $x$ is toluene in air $(\mathrm{ppm})$, and $y$ is hippuric acid in an end of shift urine sample as shown in the table. All correlation coefficients $(r)$ are statistically significant $(p<0.01)$. Values in parentheses indicate the $95 \%$ CI.

+ With a total of 303 exposed workers and 135 non-exposed workers.

$\ddagger$ Values for male workers are cited from Hasegawa et al. ${ }^{26}$

powerful determinant in almost all the symptoms (table 5).

\section{SEARCH TO IDENTIFY ANY SYMPTOMS}

ATTRIBUTABLE TO EXPOSURE TO MEK OR IPA

Among the solvents copresent with toluene, MEK and IPA were the most common when the least toxic ethyl acetate ${ }^{15}$ was excluded (table 1). Accordingly, trials were made to detect possible symptoms attributable to the toxicities of these solvents, by comparing the symptom prevalence among those exposed to MEK or IPA with those not exposed to MEK or IPA. In practice, 74 pairs of those exposed to MEK (the + MEK group) and those not exposed to MEK (the -MEK group), as well as 95 pairs of those exposed to IPA (the + IPA group) and those not exposed to IPA (the -IPA group) were established (for details of procedures, see materials and methods). Table 6 summarises the exposure of these subgroups to the solvents. It should be noted that the toluene exposure was similar between the +MEK group (GM 15.8 ppm and the - MEK group $(15 \cdot 2 \mathrm{ppm})$, and also between the +IPA group (20.3 ppm) and the -IPA group (20.3 ppm).

Comparison of subjective symptom prevalence between the +MEK group and the - MEK groups (table 7) showed that none of the symptom prevalences differed significantly ( $p>0.05)$, although the +MEK group tended to have more symptoms than the - MEK group. A similar analysis of the + IPA group in comparison with the - IPA group did not show any significant $(p>0.05)$ increase in symptoms in association with IPA exposure (table 7).

\section{REGRESSION ANALYSIS OF THE EXPOSURE- EXCRETION RELATION IN TOLUENE METABOLISM}

Toluene was present in all of the 303 solvent exposed samples studied. Accordingly, the relation of intensity of exposure to toluene with hippuric acid (a major toluene metabolite) in the end of shift urine samples was examined, ignoring the coexposures to other solvents. Calculation showed (table 8) that hippuric acid concentrations correlated significantly $(p<0.01)$ with TWA exposure concentrations of toluene, regardless of whether the values were corrected for urinary creatinine concentration or specific gravity.

The relation between toluene in air and hippuric acid in urine was examined in the + MEK group in comparison with the - MEK group. The comparison of the slopes between the two groups showed (table 9) that there was no significant $(p>0.05)$ difference in the slopes when urinary hippuric acid concentrations were either uncorrected or corrected for specific gravity, although the difference was significant $(p<0.05)$ when the concentrations were corrected for creatinine concentration. An analogous calculation showed no significant differences between the +IPA group and the -IPA group (table 9). 
Table 9 Absence of effect of coexposure to MEK or IPA on the correlation of urinary hippuric acid excretion with environmental toluene exposure

\begin{tabular}{|c|c|c|c|c|c|c|}
\hline \multirow[b]{3}{*}{ Correction for urine density } & \multicolumn{6}{|c|}{ Regression parameter } \\
\hline & \multicolumn{2}{|l|}{$\bar{a}$} & \multicolumn{2}{|l|}{$\beta$} & \multicolumn{2}{|l|}{$r$} \\
\hline & With & Without & With & Without & With & Without \\
\hline \multicolumn{7}{|c|}{ Effect of coexposure to methyl ethyl ketone: } \\
\hline & 505 & 463 & $26 \cdot 1$ & $22 \cdot 6$ & 0.549 & 0.609 \\
\hline \multirow{2}{*}{$\begin{array}{l}\text { Corrected for: } \\
\text { Creatinine (mg/g creatinine) } \\
\text { Specific gravity }(1 \cdot 016) \\
(\mathrm{mg} / \mathrm{l})\end{array}$} & 343 & 348 & $23 \cdot 7^{\star}$ & $19 \cdot 5$ & 0.783 & 0.736 \\
\hline & 327 & 320 & $16 \cdot 2$ & $14 \cdot 4$ & 0.640 & 0.628 \\
\hline \multicolumn{7}{|c|}{$\begin{array}{l}\text { Effect of coexposure to isopropyl alcohol: } \\
\text { No correction (observed value) }\end{array}$} \\
\hline \multirow{3}{*}{$\begin{array}{l}\text { Corrected for: } \\
\text { Creatinine (mg/g creatinine) } \\
\text { Specific gravity }(1 \cdot 016) \\
(\mathrm{mg} / \mathrm{l})\end{array}$} & 571 & 575 & $27 \cdot 8$ & $15 \cdot 7$ & 0.618 & 0.520 \\
\hline & 381 & 382 & $23 \cdot 2$ & $17 \cdot 6$ & $0 \cdot 841$ & 0.769 \\
\hline & 367 & 367 & $16 \cdot 3$ & $10 \cdot 7$ & 0.703 & 0.611 \\
\hline
\end{tabular}

${ }^{\star} \mathrm{p}<0.05 v$ the counterpart value. The regression lines (as defined in footnote to table 8) were calculated with 209 cases (the + MEK group and the control group, or the - MEK group and the
control group) for MEK coexposure, and with 230 cases (the + IPA group and the control control group) for MEK coexposure, and with 230 cases (the +IPA group and the control
group, or the - IPA group and the control group) for IPA coexposure. With = With coexposure group, or the - IPA group and the control group)
to MEK or IPA; without $=$ Without coexposure.

\section{Discussion}

Several articles have been published recently on the health effects of exposure to solvent mixtures. It is conceivable that the general picture of the effects will vary depending on the composition of the solvent mixture, and the intensity of the effects should be a function of the extent of exposure.

The published reports suggest two organs as the targets of toxicity-namely, the nervous system and the liver. For example, Houck et $a l^{16}$ described two cases of memory and concentration impairment after exposure to solvent mixtures during polychlorinated biphenyl clearing work. There were two types of solvent mixtures used; one consisted of alkylated benzenes and monoethanolamine, and the other was a mixture of methylchloroform and tetrachloroethylene. Unfortunately the solvent preparations the workers used were not specified. The workers were probably also exposed to polychlorinated biphenyls, although it is not likely that the symptoms were attributable to these. Lindelof et al ${ }^{17}$ found a significant increase in the prevalance of sleeping difficulties among solvent exposed workers, but no detailed description of solvent composition or intensity of exposure was given. Murata et $a^{18}$ by contrast, noted dysfuction of the autonomic and peripheral nervous system in a group of 11 solvent exposed workers. Most of them were exposed to toluene together with other solvents. Interestingly, only two of them were coexposed to $n$-hexane, a well established neurotoxin. ${ }^{19}$ The intensity of exposure was, however, not described.

Lundberg and Hakanensson ${ }^{20}$ examined paint industry workers with heavy exposure to solvent mixtures (toluene and xylenes being the main constitutents but alcohols and others were also present; the sum after the additiveness formula ${ }^{5}$ was three or more). They found no significant increase in ASAT, ALAT, or $\gamma$ GTP in serum of the exposed workers. Similarly, Chen and others ${ }^{21}$ detected no changes in ASAT, ALAT, and other enzymes in the serum of the solvent exposed workers, but $\gamma$-GTP increased in parallel with the summation index. The solvent exposure was heavy; the highest concentrations recorded were $948 \mathrm{ppm}$ for toluene, $511 \mathrm{ppm}$ for xylenes, and $138 \mathrm{ppm}$ for benzene, and the summation index was as high as $\mathbf{9 \cdot 8}$.

The present study was conducted on factory workers exposed to MEK, IPA, and ethyl acetate as well as toluene and its homologues of xylenes and ethylbenzene (table 1). The clinical signs in haematology and liver function were essentially negative (table 3 ) as is the case after exposure to toluene alone. ${ }^{22}$ Subjective symptoms during work included a floating sensation and a drunken feeling, which are related to the suppressive effects on the central nervous system, and the picture was again similar to that recorded for toluene exposure. ${ }^{22}$

Perusal of symptom profiles suggest that many workers complained of local irritation, typically to the eyes and the nose (table 5). Because MEK, one of the coexposed solvents, is a known local irritant, ${ }^{23}$ trials were done to examine if the irritation in the eyes and the nose (seen among the exposed workers) were related to exposure to MEK. Multivariate analysis showed that toluene was the most powerful determinant of eye irritation symptoms whereas MEK was the second most powerful one for nasal irritation (table 5). Further analysis controlling toluene concentration (table 6) showed that MEK was not an irritant under the exposure conditions studied. This is most probably due to the fact that MEK concentration was low in this study (GM $16 \mathrm{ppm}$; table 1) compared with the current odour and irritation based occupational exposure limit of 200 ppm..$^{523}$ In this connection, it is of interest to note the conclusion of Dick and others ${ }^{25}$ that no additivity was evident between toluene and MEK in psychmotor tests after experimental exposure of human volunteers either to toluene alone (100 ppm), to MEK alone (200 ppm), or to the combination of $50 \mathrm{ppm}$ toluene and 100 ppm MEK.

The present study showed that the urinary hippuric acid concentrations are linearly related to toluene exposure concentration even under the conditions of coexposures to MEK, IPA, and other solvents (table 8). Statistical evaluation was not possible on whether or not the slopes of the regression lines after mixture exposure were less than the slopes after exposure to toluene alone.

Comparison with the values reported in the literature ${ }^{26}$ however, did not suggest this possibility, because there is significant overlapping in the $95 \%$ confidence intervals (95\% CIs) of the regression lines (table 8). Furthermore, the comparison of slopes between those coexposed to either MEK or IPA and those not coexposed show that there was no reduction in the slopes due to the coexposure (table 9). It has previously been shown that metabolism of toluene and xylenes is independent ${ }^{14}$ when exposure intensity is below the current occupational exposure limit of $100 \mathrm{ppm}$ for each solvent, ${ }^{2324}$ although both solvents share 
methyl moiety oxidation followed by glycine conjugation in their metabolism. By contrast, both MEK and IPA have chemical structures different from the two methylated aromatics and both may undergo glucuronidation either directly or after reduction at the oxygen. ${ }^{27}$ Such differences in chemical structure and metabolism coupled with low exposure are in line with the lack of metabolic interaction of MEK and IPA with toluene.

In evaluating the lack of metabolic interaction in the present study, low concentrations of MEK (GM 16 ppm, table 1) and IPA (GM $7 \mathrm{ppm}$ ) should be taken into account. Tardif et $a l^{28}$ did not find metabolic interaction between $50 \mathrm{ppm}$ toluene and $40 \mathrm{ppm}$ xylene when human volunteers were exposed to the vapour either separately or in combination, although they detected interaction between toluene at $95 \mathrm{ppm}$ and xylene at $80 \mathrm{ppm}$. In a factory survey, Kawai et al ${ }^{29}$ found that individual solvent metabolism was not influenced by the presence of other solvents when workers were exposed to toluene, styrene, and methanol in combination at low concentrations (GMs $7 \cdot 3,4 \cdot 7$, and 15.9 ppm respectively). The present finding is consistent with those of Tardif et al, ${ }^{28}$ Kawai et $a l^{29}$ and Huang et $a^{14}$ in supporting the hypothesis that there will be no metabolic interaction when the exposure to a solvent mixture is not great. Bearing in mind that the exposure intensity in the present study is well below the current occupational exposure limit even when additiveness is assumed, it is desirable to investigate possible modification of toxicity and metabolism at exposures around the occupational exposure limit.

Thanks are due to Dr K Tanaka, Kyoto Industrial Health association, Kyoto 604, Japan for his support for this work especially for his generous supply of control cases.

1 Inoue $\mathrm{T}$, Takeuchi $\mathrm{Y}$, Hisanaga $\mathrm{N}$, Ono $\mathrm{Y}$, Iwata $\mathrm{M}$, Ogata $\mathrm{M}$, et al. A nationwide survey on organic solvent products: Part I. Homogeneous products such as thinners, degreasers and reagents. Ind Health 1983;21: ners, des.

2 Kumai $M$, Koizumi A, Saito $K$, Sakurai H, Inoue $T$, Takeuchi $\mathrm{Y}$, et al. A nationwide survey on organic solvent products: Part II. Heterogeneous products such as paints, inks and adhesives. Ind Health 1983;21: 185-97.

3 Seedorff L, Olsen E. Exposure to organic solvents-a survey on the use of solvents. Ann Occup Hyg 1990;34:371-8.

4 Hirayama T, Ikeda M. Applicability of carbon felt to the dosimetry of solvent vapor mixture. Am Ind Hyg Ass $f$ 1979;40:1091-6.

5 American Conference of Governmental Industrial Hygienists. 1992-1993 Threshold limit values and biological exposure indices. Cincinnati: ACGIH, 1992.

6 Ogata M, Taguchi T. Quantitation of urinary metabolites of toluene, xylene, styrene, ethylbenzene, benzene and phenol by automated high performance liquid chrophenol by automated high performance liquid chro263-72.
7 Jackson S. Creatinine in urine as an index of urinary excretion rate. Health Phys 1966;12:843-850.

8 Rainsford SG, Lloyd Davies TA. Urinary excretion of phenol by men exposed to vapour of benzene: a screening phenol by men exposed to vapour
test. $B r f$ Ind Med 1965;22:21-6.

9 Cai S-X, Huang M-Y, Chen Z, Liu Y-T, Jin C, Watanabe T, Nakatsuka $\mathrm{H}$, Seiji $\mathrm{K}$, Inoue $\mathrm{O}$, Ikeda M. Subjective symptom increase among dry-cleaning workers exposed to tetrachloroethylene vapor. Ind Health 1991;29: 111-21.

10 Inoue $\mathrm{T}$. A table of subjective symptoms questionnaires for solvent workers. In: Japan Industrial Health Association, eds. Health management of solvent workers. Tokyo: Japan Industrial Health Association, 1968:66-7. (In Japanese.)

11 Uchida Y, Nakatsuka H, Ukai H, Watanabe T, Liu Y-T, Huang $M-Y$, et al. Symptoms and signs in workers exposed predominantly to xylenes. Int Arch Occup exposed predominantly to xyle
Environ Health 1993;64:597-605.

12 Ukai H, Watanabe T, Nakatsuka $H$, Satoh T, Liu S-J, Qiao X, et al. Dose-dependent increase in subjective symptoms among toluene-exposed workers. Environ Res 1993;60:274-89.

13 Mizunuma K, Yasugi T, Kawai T, Horiguchi S, Ikeda M Exposure-excretion relationship of styrene and aceton in factory workers: A comparison of a lipophilic solvent and a hydrophilic solvent. Arch Environ Contam Toxicol 1993;25:129-33.

14 Huang M-Y, Jin C, Liu Y-T, Li B-H, Qu Q-S, Uchida Y, et al. Independent metabolism of toluene and xylenes in solvent workers exposed to toluene-xylene mixture vapors at low concentrations. Occup Environ Med 1994; vapors at $51: 42-6$.

15 Browning E. Toxicity and metabolism of industrial solvents. Amsterdam: Elsevier, 1965;522-5.

16 Houck P, Nebel D, Milham S Jr. Organic solvent encephalopathy: An old hazard revisited. Am $\mathcal{f}$ Ind $\mathrm{Med}$ 1992;22:109-15.

17 Lindelof B, Almkvist O, Göthe C-J. Sleep disturbances and exposure to organic solvents. Arch Environ Health 1992;47:104-6.

18 Murata K, Araki S, Yokoyama K, Maeda K. Automatic and peripheral nervous system dysfunction in workers exposed to mixed organic solvents. Int Arch Occup Environ Health 1991;63:335-40.

19 Inoue $T$, Takeuchi $Y$, Takeuchi S, Yamada S, Suzuki H, Matsushita T, et al. Industrial health survey of high inciMatsushita T, et al. Industrial health survey of high incidence of $\mathrm{n}$-hexane intoxication among vinyl sandal man-
ufacturers. fapanese fournal of Industrial Health, 1970;12:73-84. (In Japanese with English abstract.)

20 Lundberg I, Hakansson M. Normal serum activities of liver enzymes in Swedish paint workers with heavy exposure to organic solvents. $\mathrm{Br} \mathcal{F}$ Ind $M e d$ 1985;42: 596-600.

21 Chen J-D, Wang J-D, Jang J-P, Chen Y-Y. Exposure to mixtures of solvents among paint workers and biochemical alterations of liver function. $\mathrm{Br} \mathcal{F}$ Ind Med 1991;48:696-701.

22 Krasavage WJ, O'Donoghue JL, Divincenzo DG. Methyl rasavage WJ, O'Donoghue JL, Divincenzo DG. Methyl ethyl ketone. In: Clayton GD, Clayton FE eds. Patty's Industrial Hygiene and Toxicology, V

23 Deutsche Forschungsgemeinschaft. $M A K-$ and $B A T$ values 1992. Weiheim: VCM, 1992.

24 Japan Association of Industrial Health. Recommended occupational exposure limits. fapanese foumal of Industrial Health 1992;34:363-4. (In Japanese with English translation.)

25 Dick RB, Setzer JV, Wait R, Hayden MB, Taylor BJ, Tolos B, Anderson PV. Effects of acute exposures to toluene and methyl ethyl ketone on psychomotor performance. Int Arch Occup Environ Health 1984;54:91-109.

26 Hasegawa K, Shiojima S, Koizumi A, Ikeda M. Hippuric acid and $o$-cresol in the urine of workers exposed to toluene. Int Arch Occup Environ Health 1983;52 197-208.

27 Williams RT. Detoxication mechanisms. London: Chapman and Hall, 1959:43-7; 95-7.

28 Tardif R, Laparé S, Plaa GL, Brodeur J. Effect of simultaneous exposure to toluene and xylene on their respective biological exposure indices in humans. Int Arch Occup Environ Health 1991;63:279-84.

29 Kawai T, Yasugi T, Mizunuma K, Horiguchi S, Morioka I, Miyashita K, et al. Monitoring of workers exposed to a mixture of toluene, styrene and methanol vapours by mixture of toluene, styrene and methanol vapours by means of diffusive air sampling, blood analysis and
urinalysis. Int Arch Occup Environ Health 1992;63: 429-35. 